\title{
Metabolic adaptation and hormonal regulation in young rabbit does during long-term caloric restriction and subsequent compensatory growth
}

\author{
J. M. Rommers ${ }^{1}$, C. Boiti ${ }^{2}$, G. Brecchia², R. Meijerhof ${ }^{3}$, J. P. T. M. Noordhuizen ${ }^{4}$, E. Decuypere ${ }^{5}$ \\ and B. Kemp ${ }^{6}$ \\ ${ }^{1}$ Animal Sciences Group of Wageningen University and Research Centre (WUR), Applied Research, 8203 AD Lelystad, \\ The Netherlands \\ ${ }^{2}$ Dipartimento di Scienze Biopatologiche veterinarie, Sezione di Fisiologia, Università di Perugia, 06126 Perugia, Italia \\ ${ }^{3}$ Hybro, 5830 AA Boxmeer, The Netherlands \\ ${ }^{4}$ Department of Farm Animal Health, Faculty of Veterinary Medicine, University of Utrecht, The Netherlands \\ ${ }^{5}$ Laboratory for Physiology and Immunology of Domestic Animals, Department of Animal Science, Catholic University of \\ Leuven, Leuven, Belgium \\ ${ }^{6}$ Animal Sciences Group of Wageningen University and Research Centre, Department of Animal Sciences, 6700 AH \\ Wageningen, The Netherlands
} † Present address : J.M.Rommers, Animal Sciences Group of Wageningen UR, Marijkeweg 40, 6700 AH Wageningen;
e-mail : Jorine.rommers@wur.nl

\begin{abstract}
An experiment was performed to assess the metabolic adaptation and hormonal regulation in young female rabbits during long-term food restriction and subsequent compensatory growth during rearing. Feeding level was either ad libitum $(A L, n o .=52)$ or restricted $(R, n o .=52)$. From 6 to 12 weeks of age, food intake of $R$ was kept at a constant level. This resulted in an increase in relative restriction as compared with AL to 0.54of AL intake at 12 weeks of age (restriction period). Thereafter food intake gradually increased to 0.95 of AL at 17 weeks of age (recovery period). During the last 5 days before insemination at 17.5 weeks of age, all animals were fed to appetite. Blood samples were taken weekly from 6 to 17 weeks of age from 11 animals in each group. Growth rate of $R$ was reduced during the restricted period (29 (s.d.2) v. 44 (s.d.5) g/day for $R$ and $A L$, respectively; $\mathrm{P}<0.05$ ), but was higher in the recovery period (30 (s.d.3) v. 27 (s.d. 4) g/day, respectively; $\mathrm{P}<0.05)$. At first insemination, AL rabbits were heavier than $R$ (4202 (s.d.388) v. 3798 (s.d. 220) g, respectively; $\mathrm{P}<0.001)$. During the restricted period, plasma glucose was constantly lower $(\mathrm{P}<0.05)$ in $R$. Insulin levels paralleled those of glucose, being lower $(\mathrm{P}<0.05)$ in $R$ than in AL. Restriction reduced $(\mathrm{P}<0.05)$ circulating corticosterone and tri-iodothyronine (T3) levels in R. Leptin, non-esterified fatty acids, and plasma urea nitrogen levels were similar for $A L$ and $R$ during food restriction, whereas triglycerides were similar until 10 weeks of age, after which the levels were lower in $R$. During the recovery period, the food intake of the $R$ but not AL rabbits increased. Insulin was the only hormone in $R$ rabbits that had returned to levels found in AL rabbits by the 2nd week of the recovery period. Glucose, T3, and corticosterone levels returned to levels found in AL rabbits between 3 to 4 weeks after refeeding. Non-esterified fatty acids, triglycerides, and leptin were higher $(\mathrm{P}<0.05)$ in AL rabbits from 13 weeks of age onwards. The pattern of changes in the endocrine status during food restriction and compensatory growth in rabbits do conform with those from other species, although some specific changes may vary depending on the severity of food restriction and its duration.
\end{abstract}

Keywords: energy consumption, hormones, leptin, rabbits. 


\section{Introduction}

In commercial rabbit production, young rabbit does are given food ad libitum until first mating, which commonly occurs between 14 and 16 weeks of age when 0.75 to 0.80 of final body weight is reached (Lebas et al., 1986). However, with this rearing strategy does are not mature enough for reproduction. In fact, both lower reproductive performance and high replacement rate do occur, probably due to their energy deficit during first lactation (Xiccato, 1996). Voluntary food intake is considered the main limiting factor that cannot be adjusted sufficiently by management measures (Cervera et al., 1993; Parigi-Bini et al., 1996). Delaying first mating to older age results in more mature, but fatter does, in which kit mortality at kindling is increased (Partridge et al., 1986).

Recently, a different way to cope with the energy losses has been suggested by Rommers et al. (1999) in which the feeding strategy during rearing is adapted to delay sexual maturity and to stimulate body reserves and food intake capacity of young rabbit does (Rommers et al., 2001a, 2001b and 2004). Although the effects of long-term food restriction and refeeding on the regulatory mechanisms of metabolism during reduced and compensatory growth have been investigated in several animal species (Yambayamba et al., 1996; Rhind et al., 2000), the adjustments of metabolic hormones during longterm food restriction and refeeding have not been investigated in rabbits. Therefore, an experiment was performed to assess the metabolic adaptation and hormonal regulation in young rabbit does during long-term food restriction and subsequent compensatory growth by examining the time course of several key hormones, such as leptin, insulin, triiodothyronine (T3), corticosterone, and intermediate metabolites from early post weaning to first insemination at 17.5 weeks of age.

\section{Material and methods}

The Use and Care Committee of the Animal Sciences Group of Wageningen University and Research Center approved all protocols.

\section{Animals and husbandry}

Young New Zealand White rabbit does (no. = 104) bred at Applied Research, were used in the experiment. Before weaning, kits were raised in litters of nine kits. At weaning (30 days of age), from each litter, pairs of female kits with live weight deviating by less than $15 \%$ of the average litter weight, were randomly taken. Sisters were put into adjacent individual cages $(50 \times 60 \times 30 \mathrm{~cm})$ of galvanized wire net, equipped with an automatic drinker and a manual feeder. After weaning, animals were offered a standard commercial diet, containing $10 \cdot 3 \mathrm{MJ} / \mathrm{kg}$ metabolizable energy(ME) and $170 \mathrm{~g} / \mathrm{kg}$ crude protein (ABCTA, Lochem, The Netherlands). From 6 weeks of age onwards, animals were given food according to treatment until the end of the experiment. The experiment ended at first insemination (end of rearing), at 17.5 weeks of age.

Animals were housed in identical deep-pit compartments with controlled lighting. Before weaning, animals were kept at a $16-\mathrm{h}$ photoperiod and a minimum ambient temperature of $16^{\circ} \mathrm{C}$. During rearing, animals were submitted to a photoperiod of $12 \mathrm{~h}$. The first 2 weeks after weaning, a minimum ambient temperature of $18^{\circ} \mathrm{C}$ was maintained. From 2 weeks after weaning onwards, the minimum ambient temperature was set at $16^{\circ} \mathrm{C}$.

\section{Treatments}

Treatments started at 6 weeks of age when sisters were randomly assigned to one of the two treatments. Food was provided ad libitum (AL, no. $=52)$ or restricted $(R$, no. $=52)$. The $R$ rabbits were offered daily a restricted amount of food, aiming to follow a fixed body weight curve (see Figure 1) as described in a previous experiment (Rommers et al., 2001a). From 6 to 12 weeks of age, the food intake was kept between 92 and $110 \mathrm{~g} /$ day (see Figure 2). This resulted in an increase in relative restriction as compared with AL to 0.54 of AL intake at 12 weeks of age (restriction period). From 12 weeks of age onwards, food intake was increased from 115 (s.d. 4) g/day to 192 (s.d. 14) g/day (0.95 of $\mathrm{AL}$ ) at 17 weeks of age (recovery period, see Figure 2 ). In the AL rabbits voluntary food intake increased until 13 weeks of age. From this age onwards, food intake remained at approximately $200 \mathrm{~g} /$ day.

During the last 5 days before insemination (at 17.5 weeks of age), all animals were given food to appetite. $\mathrm{R}$ rabbits consumed 235 (s.d.39) $\mathrm{g}$ and

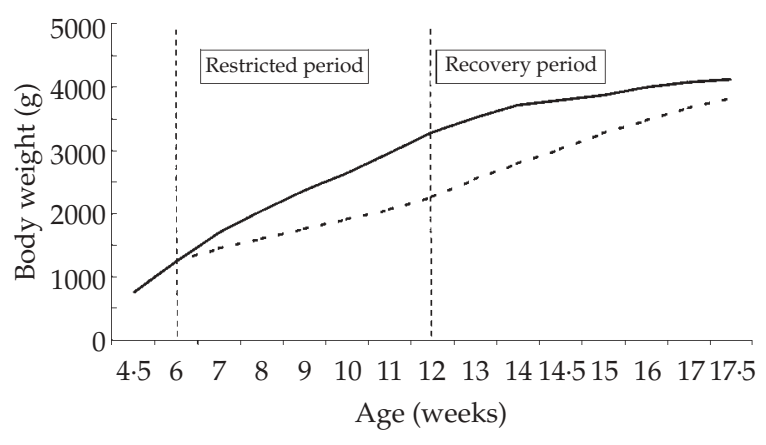

Figure 1 Fixed body weight curve during rearing for ad libitum $(\mathrm{AL},-$ ) and food restricted $(\mathrm{R},-\cdots)$ rabbits as described in Rommers et al. (2001a). 


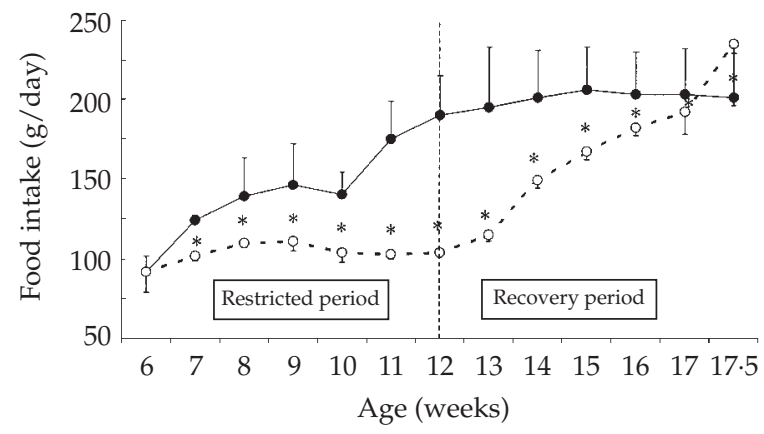

Figure 2 Mean daily food intake (g) during rearing for $a d$ libitum (AL, - no. = 52) and food restricted $(\mathrm{R},-\mathrm{O}-$ - no. $=52$ ) rabbits. $\mathrm{R}$ rabbits were given food to appetite in the last 5 days before insemination. Means \pm s.d. are presented. An asterisk indicates $P<0.05$ for $\mathrm{R}$ versus AL rabbits.

exceeded the food intake of AL-rabbits by $34 \mathrm{~g} /$ day. Food was provided to the rabbits at 13:00 h.

\section{Measurements}

Body weight and food intake. Animals were weighed individually twice weekly from weaning to first insemination. Food intake was also determined twice weekly by weighing of the feeder at beginning and end of each period and the weight of all food supplies given in between were recorded. For $\mathrm{R}$ animals, the amount of food not eaten per day was weighed weekly to determine actual food intake. Based on their actual body weight, food intake was corrected in order to follow the fixed body weight curve. If the daily supply was not eaten completely, remaining food was removed. If wastage occurred, period and cage were recorded, and food intake for this period was scored as a missing value.

Blood sampling. At the day of sampling, feeders were closed at 08:00 h. Out of the 52 animals per treatment, 11 animals were randomly taken (11 pairs of full sisters). Post-absorption blood samples were taken weekly from 6 to 17 weeks of age by ear venipuncture between 13:00 and 15:00 h, 5 to $7 \mathrm{~h}$ after feeding. Immediately upon collection into tubes containing EDTA, blood samples were centrifuged at $3000 \mathrm{~g}$ and plasma stored at $-20^{\circ} \mathrm{C}$ until assayed for metabolites and hormones.

Metabolite assays:glucose, triglycerides (TG), nonesterified fatty acids (NEFA) and plasma urea nitrogen $(P U N)$. Glucose was analysed by the glucose oxidase method using the Glucose Infinity kit from Sigma (Sigma Diagnostic Inc., St Louis, MO, USA). The TG and NEFA concentrations were analysed using enzymatic colorimetric assays from Sigma (Triglycerides Reagent Infinity) and Roche (Roche
Diagnostic GmbH, Mannheim, Germany), respectively. Plasma urea nitrogen was measured by a colorimetric assay using a kit from Dasit (Cornaredo, Italy).

Hormone assays : insulin, leptin, total T3, corticosterone. Plasma insulin concentrations were determined by the double antibody/PEG technique using a porcine insulin radio-immuno-assay (RIA) kit (Linco Research Inc., St Charles, MO, USA). The antiserum was guinea pig anti-porcine insulin, while both labelled antigen and standards used purified recombinant human insulin. Leptin concentrations were determined by double antibody RIA using the multi-species leptin kit (Linco Research Inc. ). Total T3 was assayed by RIA according to the procedure provided by the manufacturer (Immunotech, Marseille, France). The sensitivity of the assay was $0.13 \mathrm{ng} / \mathrm{ml}$, and the major analogs of T3 did not interfere with the assay. Plasma corticosterone was assayed by RIA, using CORT kit (ICN Biomedicals Inc., Costa Mesa, CA, USA). The sensitivity of the CORT assay was $0 \cdot 15 \mathrm{ng} / \mathrm{ml}$. Both dilution and recovery tests done on the assay systems for insulin, leptin, T3 and corticosterone, using five different samples of rabbit plasma showed linearity.

Statistical analysis

Body weight, growth rate, food intake, and food efficiency. Differences between treatments during the subsequent weeks of rearing were tested using the following model:

$$
Y_{i j}=\mu+T_{i}+S_{j}+(T \times S)_{i j}+e_{i j}
$$

where $Y_{i j}$ is dependent variable; $\mu=$ overall mean; $T_{i}=$ treatment $\mathrm{R}$ or $\mathrm{AL} ; S_{j}=$ pair of sisters; $(T \times S)_{i j}=$ interaction between treatment and sister pairs, and $e_{i j}$ is the residual error. In all analyses, nonsignificant interactions were deleted from the model. All statistical analyses were performed with the GLM procedure of Statistical Analysis Systems Institute (SAS, 1990). Differences between LSM were analysed by the PDIFF option of the GLM procedure of SAS. Data are presented as means and standard deviations.

Hormones and metabolites. Data relative to overall treatment effects during the time-course of the rearing period were analysed by ANOVA (Sokal and Rohlf, 1981) for repeated measurements followed by Student's $t$ test. A value of $P<0.05$ was considered significant. All statistical analyses were performed using Prism 3.0 software (GraphPad Software, Inc., San Diego, CA, USA). 
Table 1 Body weight, growth rate, food intake, and food efficiency in the restricted and recovery period during rearing for does given food ad libitum $(A L$, no. $=52)$ or restricted $(R$, no. $=52)$

\begin{tabular}{|c|c|c|c|c|}
\hline & \multicolumn{4}{|c|}{ Feeding level } \\
\hline & \multicolumn{2}{|c|}{ Ad libitum } & \multicolumn{2}{|c|}{ Restricted } \\
\hline & Mean & s.d. & Mean & s.d. \\
\hline \multicolumn{5}{|l|}{ Restricted period (6 to 12 weeks of age) } \\
\hline Body weight at start (6 weeks of age) (g) & 1295 & 108 & 1287 & 116 \\
\hline Food intake (g/day) & $152^{\mathrm{a}}$ & 18 & $106^{\mathrm{b}}$ & 6 \\
\hline Growth rate (g/day) & $44^{\mathrm{a}}$ & 5 & $29^{\mathrm{b}}$ & 2 \\
\hline Food efficiency (g gain/g food) & $0 \cdot 29$ & $0 \cdot 2$ & $0 \cdot 27$ & $0 \cdot 3$ \\
\hline \multicolumn{5}{|l|}{ Recovery period (12 to 17 weeks of age) } \\
\hline Body weight at 12 weeks of age (g) & $3157^{\mathrm{a}}$ & 287 & $2193^{\mathrm{b}}$ & 111 \\
\hline Food intake (g/day) & $202^{\mathrm{a}}$ & 25 & $159^{\mathrm{b}}$ & 4 \\
\hline Growth rate (g/day) & $27^{\mathrm{a}}$ & 4 & $30^{\mathrm{b}}$ & 3 \\
\hline Food efficiency ( $\mathrm{g}$ gain $/ \mathrm{g}$ food) & $0 \cdot 13$ & 0.9 & $0 \cdot 19$ & 0.04 \\
\hline Body weight 17 weeks of age $(\mathrm{g})$ & $4101^{\text {a }}$ & 376 & $3563^{\mathrm{b}}$ & 135 \\
\hline Body weight at insemination ( 17.5 weeks) $(\mathrm{g})$ & $4202^{\mathrm{a}}$ & 388 & $3798^{\mathrm{b}}$ & 220 \\
\hline
\end{tabular}

a,b Means with a different letter in a row are significantly different $(P<0.05)$.

\section{Results}

Body weight, growth rate, and food efficiency

Body weight, growth rate, and food efficiency during the restricted and recovery periods are presented in Table 1 . Body weight at weaning and at start of the experiment (6 weeks of age) was similar for both treatments. At first insemination (17.5 weeks of age), $\mathrm{R}$ rabbits were smaller than AL (3798 (s.d. 220) $\mathrm{g}$ and 4202 (s.d.388) g, respectively; $P<0.001$ ).

Growth rate during rearing is presented in Figure 3. Rabbits that were given food ad libitum had a high growth rate until approximately 11 weeks of age (between 45 and $48 \mathrm{~g}$ /day). Thereafter, body growth decreased and remained constant from 15 weeks of

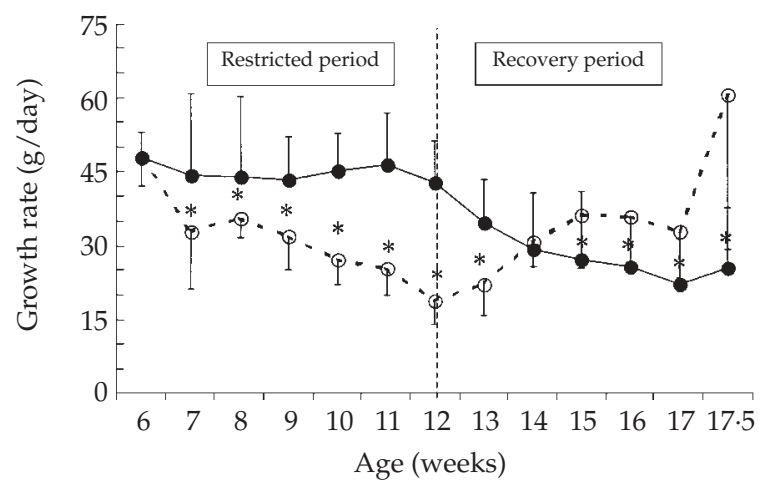

Figure 3 Body growth during rearing for ad libitum (AL, - no. $=52)$ and food restricted $(\mathrm{R},--\mathrm{O}-\cdot$ no. $=52)$ rabbits. Means \pm s.d. are presented. An asterisk indicates $P<0.05$ for $\mathrm{R}$ versus AL rabbits. age onwards (between 20 and $25 \mathrm{~g} /$ day). Growth rate of the $\mathrm{R}$ rabbits decreased to 19 (s.d. 4.9) g/day at 12 weeks of age in the restricted period as a result of the food restriction. During the recovery period, growth rate was aimed to follow the slope of the AL curve (see Figure 1) in order to compensate for the loss in protein (Ledin, 1984) and to stimulate sexual development and puberty (van den Broeck and Lampo, 1977). Increased food intake resulted in an increased growth rate with a growth spurt during the last 5 days before insemination when rabbits were given food to appetite (60 (s.d. 30) g/day).

Food efficiency was affected by feeding level. From weaning to first insemination, ad libitum feeding resulted in a lower food efficiency compared with restrictive feeding $(0.23$ (s.d. 0.23$)$ and 0.26 (s.d. 0.21$)$ for AL and $\mathrm{R}$, respectively; $P<0.05$ ).

\section{Metabolic parameters}

The plasma profiles of glucose, TG, NEFA, and PUN during the rearing period from week 6 to week 17 of age in AL and R rabbits are shown in Figure 4. Mean plasma glucose concentrations were lower $(P<0.05)$ in $\mathrm{R}$ than in AL rabbits from 8 to 14 weeks of age during both the restriction and recovery period (Figure 4a). Only in the last 3 weeks of rearing was glucose restored to control levels in $\mathrm{R}$ rabbits, mainly because glucose levels in AL rabbits dropped to $R$ levels.

Triglycerides were higher $(P<0.05)$ in $\mathrm{R}$ than in AL rabbits at the beginning of the restriction period from week 7 to week 8 (Figure $4 \mathrm{~d}$ ). From week 11 
onwards, $\mathrm{TG}$ in $\mathrm{R}$ rabbits gradually decreased to values that, at week 17 , were almost three-fold lower than those of $\mathrm{AL}(P<0 \cdot 05)$. In $\mathrm{AL}$ rabbits, TG increased with advancing age. In both treatments, NEFA showed a similar pattern as their level

(a)

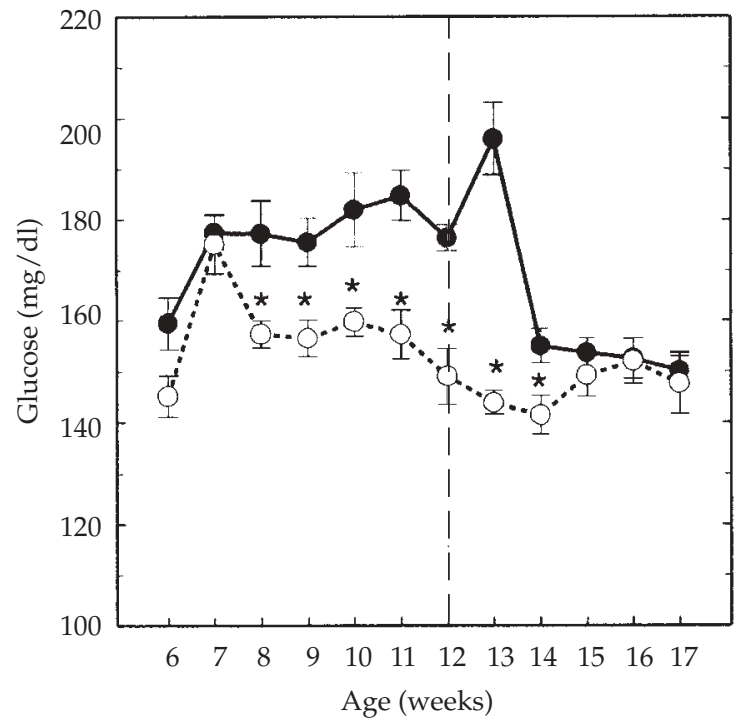

(c)

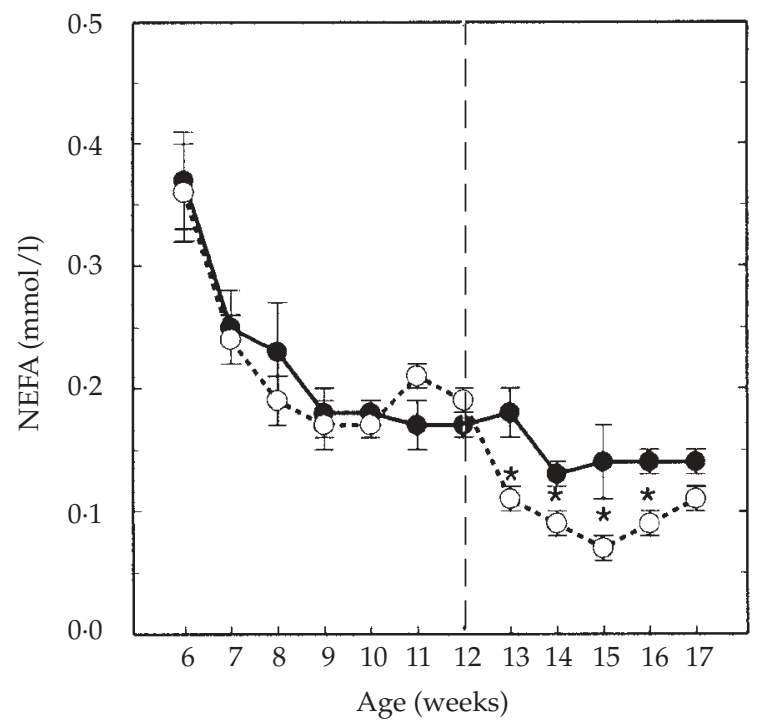

dropped $(P<0.05)$ with advancing age, from 0.38 $\mathrm{mmol} / \mathrm{l}$ at week 6 to about $0.1 \mathrm{mmol} / \mathrm{l}$ at week 17 (Figure 4c). In the recovery period from week 13 to 16 , NEFA was lower $(P<0.05)$ in $\mathrm{R}$ rabbits compared with AL ones. PUN levels were constantly lower

(b)

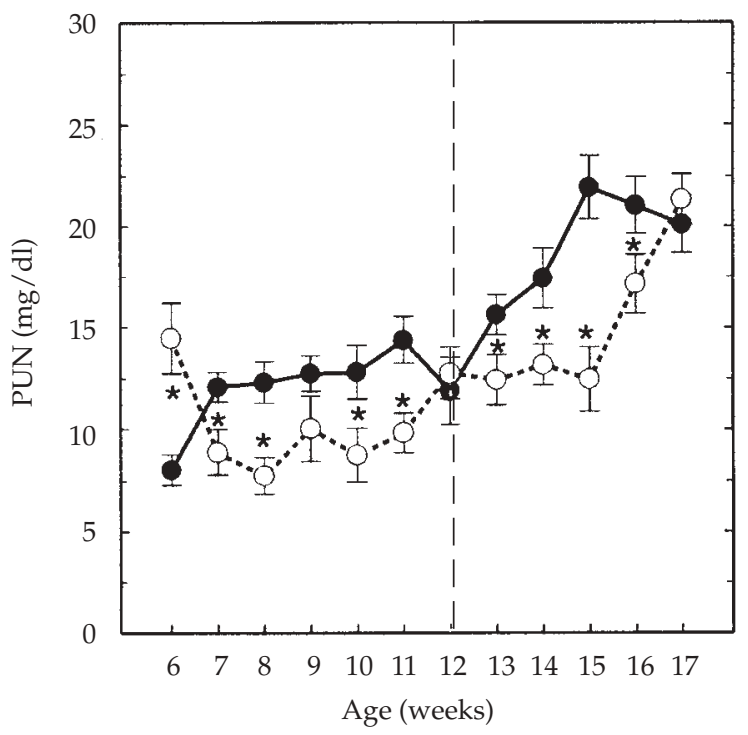

(d)

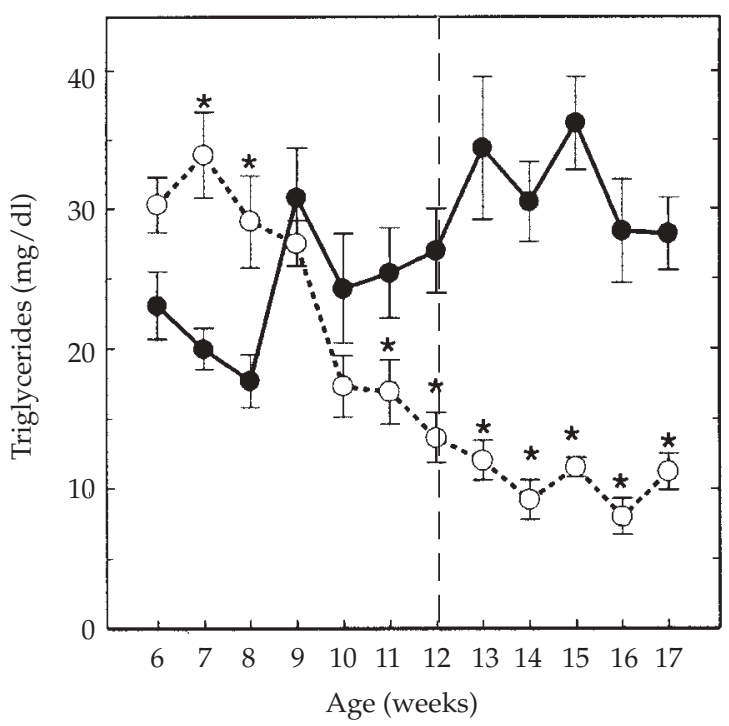

Figure 4 Metabolic parameters showing (a) glucose, (b) plasma urea nitrogen (PUN), (c) non-esterified fatty acids (NEFA), and (d) triglycerides during the rearing period from week 6 to week 17 of age in rabbits given food ad libitum (AL, - - ) or restricted $(\mathrm{R}, \cdots \mathrm{O} \cdots)$. The vertical line separates the restriction phase from the following compensatory growth phase. In week 17, R rabbits were given food ad libitum. Within each figure, the values, are means \pm s.e. for 11 animals per treatment group per week. An asterisk indicates $P<0 \cdot 05$ for $\mathrm{R}$ versus AL rabbits. 
$(P<0.05)$ in $\mathrm{R}$ compared with AL rabbits, during the restriction as well as in the recovery period (Figure $4 b)$.

(a)

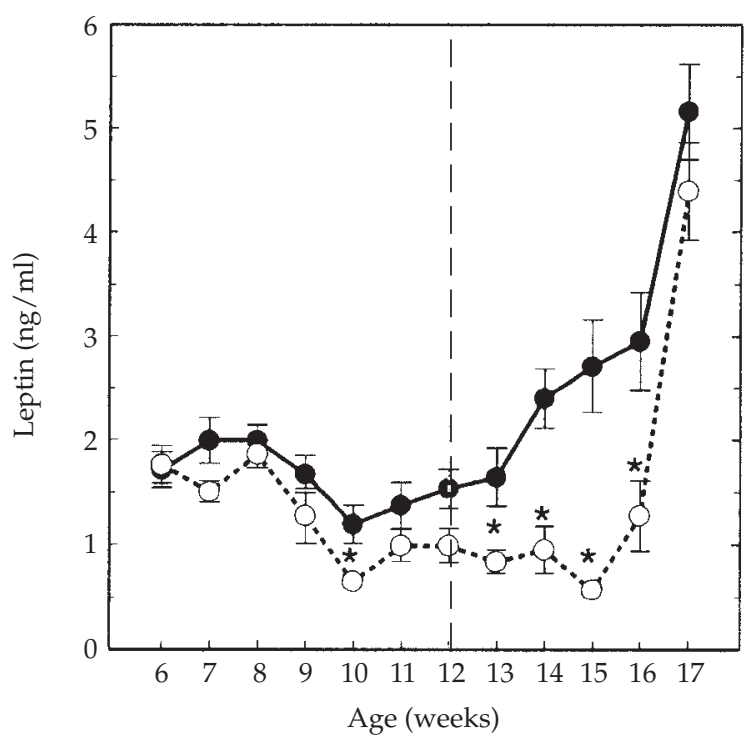

(c)

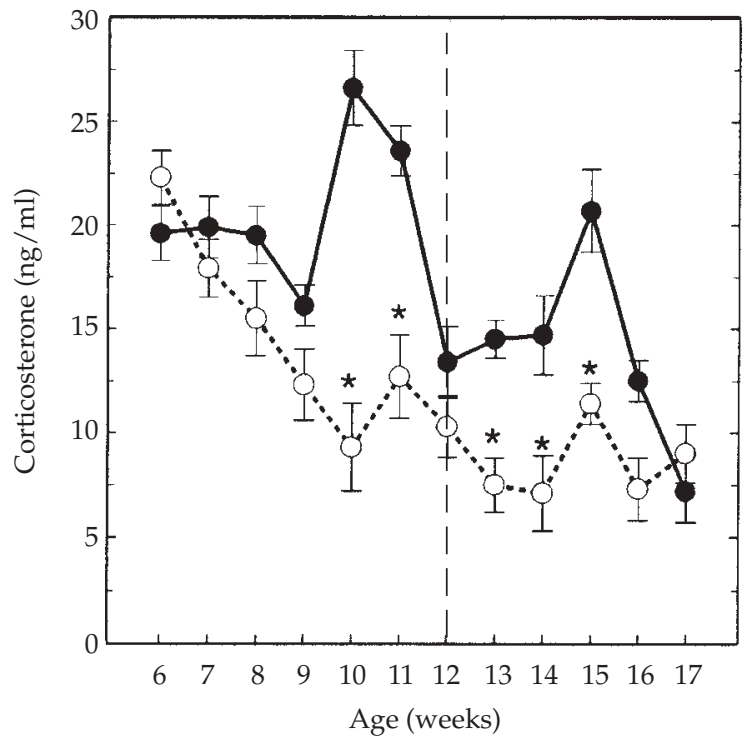

Hormonal parameters

The blood profiles of immunoreactive leptin, insulin, $\mathrm{T} 3$ and corticosterone during the rearing period from

(b)

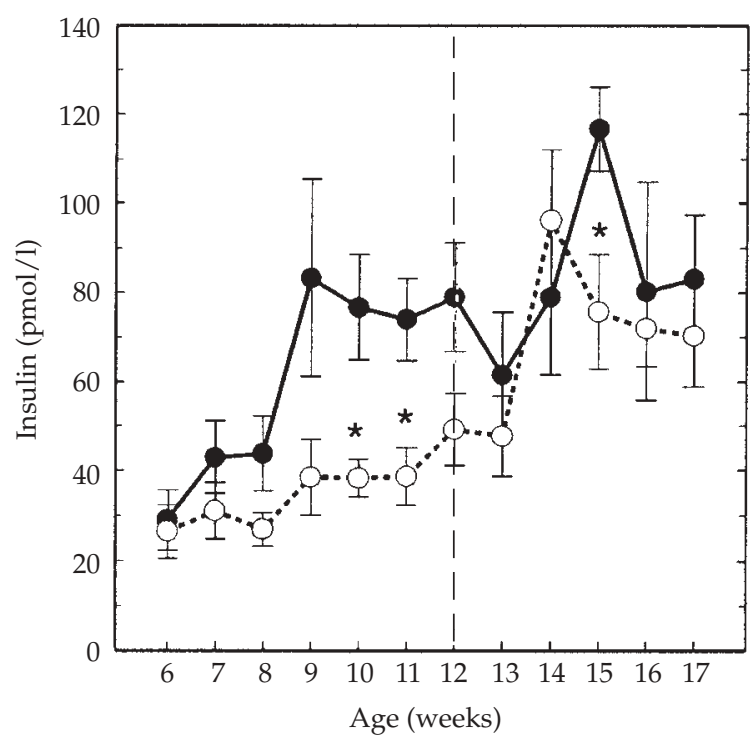

(d)

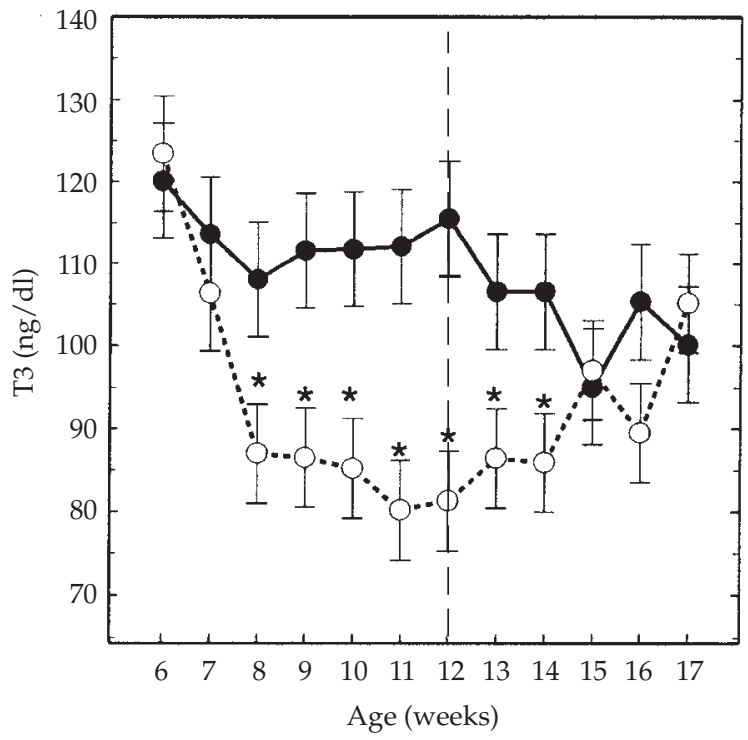

Figure 5 Endocrine parameters showing immunoreactive (a) leptin, (b) insulin, (c) corticosterone, and (d) tri-iodothyronine (T3) during the rearing period from week 6 to week 17 of age in rabbits given food ad libitum (AL, $\longrightarrow-$ ) or restricted (R, .....-...). The vertical line separates the restriction phase from the following compensatory growth phase. In week $17, \mathrm{R}$ rabbits were given food ad libitum. Within each figure, the values, are means \pm s.e. for 11 animals per treatment group per week. An asterisk indicates $P<0 \cdot 05$ for $\mathrm{R}$ versus AL rabbits. 
week 6 to week 17 of age in rabbits given food ad libitum (AL) or restricted (R) are shown in Figure 5. Leptin levels were similar for both groups until 10 weeks (Figure 5a). From 10 weeks onwards, leptin levels gradually increased in $\mathrm{AL}$, but not in $\mathrm{R}$ rabbits. In the last week of rearing, when $\mathrm{R}$ rabbits were given food to appetite, leptin concentrations increased five-fold and were similar to that of AL.

An increase in circulating insulin concentrations was observed with advancing age in both $\mathrm{AL}$ and $\mathrm{R}$ rabbits (Figure 5b). However, insulin was constantly lower in $\mathrm{R}$ than AL rabbits during food restriction. In the recovery period, insulin levels of $\mathrm{R}$ rabbits rose to values close to those of ad libitum animals.

Plasma corticosterone in AL rabbits showed a high variability between successive weeks, but profiles gradually declined with age (Figure 5c). Food restriction reduced circulating corticosterone in $R$ rabbits from 10 until 15 weeks of age. Corticosterone concentrations in the last 2 weeks of rearing were similar for both treatments, due to a sharp decline in AL rabbits.

Compared with AL rabbits, food restriction decreased plasma concentrations of T3 from 8 weeks of age until 14 weeks of age (Figure 5d). During the last 3 weeks of rearing (recovery period) circulating concentrations of T3 were restored to control levels.

\section{Discussion}

In our study, we used an adapted feeding plan in which food intake was reduced from 6 to 12 weeks of age to hinder protein deposition. From 12 weeks of age onwards, rabbits were given increased amounts of food so that they could match growth of rabbits given food ad libitum. The purpose of this feeding plan was to obtain a more mature (older aged) rabbit, but prevent the excessive fat deposition that commonly occurs after 12 weeks of age (de Blas et al., 1977; Deltoro and Lopez, 1985). This was done by obtaining the same body weight at 17.5 weeks as that of AL rabbits at 14.5 weeks of age. However, in the recovery period $\mathrm{R}$ rabbits were not given food to appetite and metabolic and hormone profiles are not as distinctive as under ad libitum feeding conditions. In our study, the general post-absorption state of metabolites and metabolic hormone levels was studied.

The effect of food restriction on the regulatory mechanisms of metabolism during reduced and compensatory growth has been investigated in several animal species (Yambayamba et al., 1996; Rhind et al., 2000), but not in rabbits. Although the basic underlying physiological responses to underfeeding might be common to all mammals, our data on adjustment of metabolic hormones in the rabbit during long-term food restriction and refeeding are new. Moreover, our energy restriction spanned over a relatively long period of time, from early post weaning up to puberty, during the development of several key organs, such as liver and kidneys (Cantier et al., 1969; Deltoro and Lopez, 1985).

Glucose, the body's major energy source, was lower in $\mathrm{R}$ rabbits throughout most of the restriction and the recovery phase due to their lower amount of food intake compared with the AL rabbits. That decreased nutrient intake reduces glucose concentration has also been reported in other species subjected to low planes of nutrition (Booth et al., 1996; Ouellet et al., 2001).

As a consequence of the restricted food intake, plasma immunoreactive insulin was decreased. Interestingly, insulin is the only hormone that in $\mathrm{R}$ rabbits was restored to levels found in AL rabbits in the 2 nd week of the recovery period. This finding is in agreement with Hornick et al. (2000), who stated that normalization of plasma insulin levels was one of the first features occurring within the first days of refeeding, although in our study, plasma insulin levels were restored to control levels later in time.

Insulin is a key player in the control of intermediary metabolism influencing both carbohydrate and lipid metabolism, as well as protein and mineral metabolism. Since there is evidence of active transfer of insulin into the brain, this hormone could have a rôle in signalling the metabolic state of the animal and in the regulation of appetite (Schwartz et al., 1992). Insulin inhibits breakdown of fat in adipose tissue by inhibiting the intracellular lipase that hydrolyses TG to release fatty acids. Insulin facilitates entry of glucose into adipocytes, and within those cells, glucose can be used to synthesize glycerol. This glycerol, along with the fatty acids delivered from the liver, is used to synthesize TG within the adipocyte. By these mechanisms, insulin is involved in further accumulation of TG in fat cells. Low insulin facilitates lypolysis while high insulin stimulates de novo lipogenesis (Bruckert and Dejager, 1994; Buczkowska and Jarosz-Chobot, 2001).

Several hormones link growth, metabolism and energy homeostasis (Hornick et al., 2000). Between these, leptin, produced and secreted by adipose cells, is an important component in the long-term regulation of body weight and body fat mass content. In $\mathrm{R}$ rabbits, immunoreactive leptin concentrations in plasma were lower compared with 
$\mathrm{AL}$ rabbits, especially during the compensatory growth phase after week 12 . The gradual increase of the circulating leptin with age in AL rabbits may reflect increased adiposity at puberty (around week 12 in rabbit does) probably under the influence of oestrogen as shown in pigs (Barb et al., 2001a). In AL rabbits, an increased fat deposition has been observed from $0 \cdot 20$ to $0 \cdot 24$ of empty body weight between 14.5 and 17.5 weeks of age (Rommers et al., 2001a). Our data on leptin concentrations during food restriction are in agreement with other studies where low nutritional intake prolonged over a longer period induced a similar effect, as demonstrated in pre-pubertal gilts (Barb et al., 2001b), and ruminants (Chilliard et al., 2000).

All other hormone parameters here examined are more related to the body growth or body composition status and are in agreement with other studies in heifers (Yambayamba et al., 1996), bulls (Hornick et al., 1998;) sows (Buonomo and Baile, 1991; Booth et al., 1996; Quesnel et al., 1998) and chickens (Bruggeman et al., 1997).

In the present work, the adrenal axis of $\mathrm{R}$ rabbits during both the restriction phase and the subsequent compensatory growth appears to be depressed as corticosterone plasma concentrations were lower compared with AL rabbits. The low corticosterone circulating levels may counteract the excessive catabolic rate of basal metabolism evoked by prolonged food restriction similarly to that found in pre-pubertal gilts by Booth et al. (1994). The lower activity of the adrenal axis found in $\mathrm{R}$ rabbits during compensatory growth may reflect its responsive adaptation to a long-term stressful condition being applied in the early stage of life (Sapolsky, 1992). Conversely, corticosteroids were found to increase under food restriction in the pig (Prunier and Quesnel, 2000) but decrease in chickens (Zulkifli et al., 1995). These discrepancies may reflect speciesspecific differences or diverse levels of stress evoked by the bleeding methods as well as dissimilar timing of blood collection, either pre- or post-prandial, in relation to feeding.

In our experimental model, NEFA declined similarly in AL as well as in R rabbits until 12 weeks of age. At the end of the restricted period, food intake of the $R$ rabbits still covered maintenance requirement. Although growth rate was reduced, $\mathrm{R}$ rabbits still grew and could not have been in negative energy balance. This implies similar NEFA levels for $\mathrm{R}$ and $\mathrm{AL}$ rabbits. However, during most of the recovery phase, NEFA were lower in $\mathrm{R}$ than in AL rabbits. NEFA are released by the action of hormone sensitive lipase on TG stores in adipose tissue and increased NEFA concentrations are indicative of negative energy balance (Emery et al., 1992; Rukkwamsuk et al., 1999). Triglycerides were also lower in $\mathrm{R}$ rabbits during the recovery period. Hence, decreased circulating NEFA and TG during compensatory growth may reflect redirection of fat metabolism towards reduced lipolysis due to increased plasma insulin concentrations.

The observation that PUN levels were constantly lower in food restricted rabbits throughout the experiment suggests that an alteration of protein metabolism occurred during dietary restriction as well as the recovery period. In energy deficient rabbits, protein-sparing adaptation comes into play to limit turn-over and degradation of protein, whereas, during compensatory growth stimulated by refeeding, increased protein synthesis is associated with decreased nitrogen excretion and lower plasma urea. These findings, which are in agreement with those reported in other species (Sainz et al., 1994; Wykes et al., 1996; Tauson et al., 2002), may provide further evidence for the preferential deposition of lean meat instead of fat tissue in young rabbits undergoing the food restriction (Rommers et al., 2001a).

During food restriction, and for some weeks also during the recovery period, T3 levels were lower than in AL rabbits. Restricted food intake induces animals to spare energy by decreasing basal metabolism (Hornick et al., 2000). Food restriction followed by re-feeding affects thyroidal secretion in cattle (Gerrits et al., 1998; Hornick et al., 1998; CassarMakel et al., 2001), swine (Buonomo and Baile, 1991; Booth et al., 1994), and poultry (McMurtry et al., 1988; Buyse et al., 2002). In many species, lower energy intake reduces thyroid function. In our study, T3 concentrations rose to similar levels as AL rabbits after 3 weeks of the recovery period.

In conclusion, long-term nutrient deficiency during development has major neuro-endocrine consequences provoking prominent homeostatic reactions of the corticotropic, leptinergic and thyrotropic axes which persist during compensatory growth, at least up to sexual maturity. During food restriction basal metabolism is reduced owing to the reduction of several anabolic hormones such as T3, and insulin. This pattern of changes in the endocrine status during food restriction is typical and current data in rabbits do confirm those derived from other species, although some specific changes may vary depending on the severity and duration of food restriction. In the recovery period, only insulin adapted within 2 weeks after refeeding. During rearing, hormone and metabolite profiles were 
markedly different for the two treatments. Rabbits that were food restricted during rearing as in this study, maintained a higher food intake during first gestation and lactation period and these rabbits produced more kits and milk during the first parity (Rommers et al., 2004). How the metabolic and hormonal profiles during rearing are linked to subsequent voluntary food intake and reproductive performance needs further research.

\section{Acknowledgements}

The authors thank Paul Harmelink and Hans van Schaik for their assistance in taking blood samples and taking care of the animals during the experiment.

This work was partially supported by a grant from the Italian MIUR (PRIN Prot. N. MM07193821_005).

\section{References}

Barb, C. R., Barrett, J. B., Kraeling, R. R. and Rampacek, G. B. 2001b. Serum leptin concentrations, luteinizing hormone and growth hormone secretion during feed and metabolic fuel restriction in prepuberal gilts. Domestic Animal Endocrinology 20: 47-63.

Barb, C. R., Kraeling, R. R. and Rampacek, G. B. 2001a. Nutritional regulators of the hypothalamic-pituitary axis in pigs. Journal of Reproduction and Fertility Supplement 58: 1-15.

Blas, J. C. de, Torres, A., Fraga, J., Perez, E. and Galvez, J. F. 1977. Influence of weight and age on the body composition of young doe rabbits. Journal of Animal Science 45: 48-53.

Booth, P. J., Cosgrove, J. R. and Foxcroft, G. R. 1996 Endocrine and metabolic responses to realimentation in feed-restricted perpubertal gilts: association among gonadotropins, metabolic hormones, glucose, and uteroovarian development. Journal of Animal Science 74: 840-848.

Booth, P. J., Craigon, J. and Foxcroft, G. R. 1994. Nutritional manipulation of growth and metabolic and reproductive status in prepubertal gilts. Journal of Animal Science 72: 2415-2424.

Broeck, L. van den and Lampo, P. H. 1977. Influnece de trois niveaux d'alimentation de lapines futures reproductrices sur l'ardeur sexuelle et la fertilité à 4 moins. Annales de Zootechnie 26: 565-574.

Bruckert, E. and Dejager, S. 1994. [Lipoprotein lipase: a key enzyme of lipid metabolism.] La Revue-du-practicien 44: 1487-1493.

Bruggeman, V., Vanmontfort, D., Renaville, R., Portetelle, D. and Decuypere, E. 1997. The effect of food intake from two weeks of age to sexual maturity on plasma growth hormone, insulin-like growth factor-I, insulin-like growth factor-binding proteins, and thyroid hormones in female broiler breeder chickens. General and Comparative Endocrinology 107: 212-220.

Buczkowska, E. O. and Jarosz-Chobot, P. 2001. [Insulin effect on metabolism in skeletal muscles and the role of muscle regulation of glucose homeostasis.] Przegladlekarski 58: 782-787.
Buonomo, F. C. and Baile, C. A. 1991. Influence of nutritional deprivation on insulin-like growth factor I, somatotropin, and metabolic hormones in swine. Journal of Animal Science 69: 755-760.

Buyse, J., Janssens, K., Geyten, S. van der, As, P. van, Decuypere, E. and Darras, V. M. 2002. Pre- and postprandial change in plasma hormone and metabolite levels and hepatic deiodenase activities in meal-fed broiler chickens. British Journal of Nutrition 88: 641-653.

Cantier, J., Vezinhet, A., Rouvier, R. and Dauzier, L. 1969. Allométrie de croissance chez le lapin (Oryctolagus cuniculus). I. Principaux organes et tissus. Annales de Biologie Animale, Biochimie et Biophysique 9: 5-39.

Cassar-Malek, I., Kahl, S., Jurie, C. and Picard, B. 2001. Influence of feeding level during postweaning growth on circulating concentrations of thyroid hormones and extrathyroidal 5'-deiodination in steers. Animal Science 79: 2679-2687.

Cervera, C., Fernandez-Carmona, J., Viudes, P. and Blas, E. 1993. Effect of remating interval and diet on the performance of female rabbits and their litters. Animal Production 56: 399-405.

Chilliard, Y., Ferlay, A., Faulconnier, Y., Bonnet, M., Rouel, J. and Bocquier, F. 2000. Adipose tissue metabolism and its role in adaptations to undernutrition in ruminants. Proceedings of the Nutrition Society 59: 127-134.

Deltoro, J. and Lopez, A. M. 1985. Allometric changes during growth in rabbits. Journal of Agricultural Science, Cambridge 105: 339-346.

Emery, R. S., Liesman, J. S. and Herdt, T. H. 1992. Metabolism of long chain fatty acids in ruminant liver. Animal Nutrition Physiology 122: 832-837.

Gerrits, W. J. J., Decuypere, E., Verstegen, M. W. A. and Karabinas, V. 1998. Effect of protein and protein-free energy intake on plasma concentrations of insulin-like growth factor I and thyroid hormones in preruminant calves. Journal of Animal Science 76: 1356-1363.

Hornick, J. L., Eenaeme, C. van, Diez, M., Minet, V. and Istasse, L. 1998. Different periods of feed restriction before compensatory growth in Belgian Blue bulls. II. Plasma metabolites and hormones. Journal of Animal Science 76: 260-271.

Hornick, J. L., Eenaeme, C. van, Gérard, O., Dufrasne, I. and Istasse, L. 2000. Mechanisms of reduced and compensatory growth. Domestic Animal Endocrinology 19: 121-132.

Lebas, F., Coudert, R., Rouvier, R. and Rochambeau, H. de. 1986. The rabbit. Husbandry, health and production. FAO Animal Production and Health Series no. 21, Rome.

Ledin, I. 1984. Effect of restricted feeding and realimentation on compensatory growth, carcass composition and organ growth in rabbit. Annales de Zootechnie 33: 33-50.

McMurtry, J. P., Plavnik, I., Rosebrough, R. W., Steele, N. C. and Proudman, J. A. 1988. Effect of early feed restriction in male broiler chicks on plasma metabolic hormones during feed restriction and accelerated growth. Comparative Biochemistry and Physiology 91: 67-70. 
Ouellet, D. R., Seoane, J. R., Bernier, J. F. and Lapierre, H. 2001. Effect of feed restriction on plasma concentration of hormones and metabolites in steers fed grass silage. Canadian Journal of Animal Science 81: 553-561.

Parigi-Bini, R., Xiccato, G., Dalle Zotte, A., Carazzolo, A. Castellini, C. and Stradaiolli, G. 1996. Effect of re-mating and diet on the performance and energy balance of rabbit does. Proceedings of the sixth world rabbit congress, Toulouse, pp. $253-258$.

Partridge, G. G., Daniels, Y. and Fordyce, R. A. 1986. The effect of energy intake during pregnancy in doe rabbits on pup birth weight, milk output and maternal body composition change in the ensuing lactation. Journal of Agricultural Science, Cambridge 107: 697-708.

Prunier, A. and Quesnel, H. 2000. Nutritional influences on the hormonal control of reproduction in female pigs. Livestock Production Science 63: 1-16.

Quesnel, H., Pasquier, A., Mounier, A. M., Louveau, I. and Prunier, A. 1998. Influence of feed restriction in primiparous lactating sows on body condition and metabolic parameters. Reproduction, Nutrition, Development 38: $261-274$.

Rhind, S. M., McMillen, S. R., Duff, E., Kyle, C. E. and Wright, S. 2000. Effect of long term feed restriction on seasonal endocrine changes in Soay sheep. Physiology and Behavior 71: 343-351.

Rommers, J. M., Kemp, B., Meijerhof, M. and Noorduizen, J. P. T. M. 1999. Rearing management of rabbit does: a review. World Rabbit Science 7: 125-138.

Rommers, J. M., Kemp, B., Meijerhof, R. and Noordhuizen, J. P. T. M. 2001b. The effect of litter size before weaning on subsequent body development, feed intake, and reproductive performance of young rabbit does Journal of Animal Science 79: 1973-1982.

Rommers, J. M., Meijerhof, R., Noordhuizen, J. P. T. M and Kemp, B. 2001a. Effect of different feeding levels during rearing and age at first insemination on body development, body composition, and puberty. characteristics. World Rabbit Science 9: 101-108.

Rommers, J. M., Meijerhof, R., Noordhuizen, J. P. T. M and Kemp, B. 2004. Effect of body weight and age at first insemination on performances during subsequent reproduction in rabbit does. Reproduction, Nutrition, Development In press.

Rukkwamsuk, T., Kruip, T. A. and Wensing, T. 1999. Relationship between overfeeding and overconditioning in the dry period and the problems of high producing dairy cows during the postparturient period. Veterinary Quarterly 21: 71-77.

Sainz, R. D., Hosing, B. J., Hart, F. J. and Spencer, G. S. G. 1994. Effects of growth hormone-releasing factors and cottonseed meal on hormones and metabolites in plasma from lambs fed lucerne chaff ad libitum. Australian Journal of Agricultural Research 45: 1125-1135.

Sapolsky, R. M. 1992. Stress, the aging brain and the mechanism of neuron death. MIT Press, Cambridge, MA.

Schwartz, M. W., Figlewicz, D. P., Baskin, D. G., Woods, S. C. and Porte, D. 1992. Insulin in the brain: a hormonal regulator of energy balance. Endocrine Reviews 13: 387-414.

Sokal, R. R. and Rohlf, F. J. 1981. Biometry. W. H. Freeman and Co., New York.

Statistical Analysis Systems Institute. 1990. SAS/STAT user's guide. SAS Institute Inc., Cary, NC.

Tauson, A. H., Chwalibog, A. and Ahlstrøm, Ø. 2002. Substrate oxidation in male blue foxes (Alopex lagopus) during feeding, fasting and realimentation. Journal of Nutrition 132: 1793-1795.

Wykes, L., Fiorotto, M., Burrin, D. G., Del-Rosario, M., Frazer, M. E., Pond, W. G. and Jahoor, F. 1996. Chronic low protein intake reduces tissue protein synthesis in a pig model of protein malnutrition. Journal of Nutrition 125: 1481-1488.

Xiccato, G. 1996. Nutrition of lactating does. Proceedings of the sixth world rabbit congress, Toulouse, vol. 1, pp. 29-47.

Yambayamba, E. S., Price, M. A. and Foxcroft, G. R. 1996. Hormonal status, metabolic changes, and resting metabolic rate in beef heifers undergoing compensatory growth. Journal of Animal Science 74: 57-96.

Zulkifli, I., Siegel, S., Mashaly, M. M., Dunnington, E. A. and Siegel, P. B. 1995. Inhibition of adrenal steroidogenesis, neonatal feed restriction, and pituitary-adrenal axis response to subsequent fasting in chickens. General and Comparative Endocrinology 97: 49-56.

(Received 13 February 2004-Accepted 20 May 2004) 